\title{
3D ground-penetrating radar imaging of ice complex deposits in northern East Siberia
}

\author{
Stephan Schennen ${ }^{1}$, Jens Tronicke ${ }^{1}$, Sebastian Wetterich ${ }^{2}$, Niklas Allroggen ${ }^{1}$, \\ Georg Schwamborn², and Lutz Schirrmeister ${ }^{2}$
}

\begin{abstract}
Ice complex deposits are characteristic, ice-rich formations in northern East Siberia and represent an important part in the arctic carbon pool. Recently, these late Quaternary deposits are the objective of numerous investigations typically relying on outcrop and borehole data. Many of these studies can benefit from a 3D structural model of the subsurface for upscaling their observations or for constraining estimations of inventories, such as the local carbon stock. We have addressed this problem of structural imaging by $3 \mathrm{D}$ groundpenetrating radar (GPR), which, in permafrost studies, has been primarily used for 2D profiling. We have used a 3D kinematic GPR surveying strategy at a field site located in the New Siberian Archipelago on top of an ice complex. After applying a 3D GPR processing sequence, we were able to trace two horizons at depths below $20 \mathrm{~m}$. Taking available borehole and outcrop data into account, we have interpreted these two features as interfaces of major lithologic units and derived a 3D cryostratigraphic model of the subsurface. Our data example demonstrated that a 3D surveying and processing strategy was crucial at our field site and showed the potential of 3D GPR to image geologic structures in complex ice-rich permafrost landscapes.
\end{abstract}

\section{INTRODUCTION}

Large areas of the northern East Siberian arctic are underlain by icerich permafrost. In this nonglaciated environment, so-called ice complexes represent an essential component of the periglacial landscape and play an important role for understanding Quaternary depositional, stratigraphic, and paleoenvironmental dynamics (Schirrmeister et al., 2011; Grosse et al., 2013). They consist of fine-grained, silty sediments, which are characterized by ice oversaturation, and they contain a considerable amount of organic matter; typically 3-8 g total organic carbon (TOC) content per gram dry sediment (Strauss et al., 2012). Due to arctic warming, permafrost thaw might transform these ice complex formations from a long-term carbon sink (Strauss et al., 2013) to a carbon source. Thus, these deposits potentially play a major role in positive feedback processes of ongoing climate change and arctic warming in particular.

Numerous studies have recently focused on ice complex deposits, which are often well-exposed along coasts and riverbanks in the northern East Siberian lowlands. Using methods from micropaleontology, geochemistry, sedimentology, and remote sensing, these studies aim at, e.g., reconstructing paleoenvironmental conditions (Andreev et al., 2011), approximating the permafrost carbon stock (Tarnocai et al., 2009; Strauss et al., 2012; Hugelius et al., 2014), and estimating the exposure and response to arctic warming (Ulrich et al., 2014). Typically, such studies focus on the uppermost meter of the subsurface and/or outcrops and would benefit from a more detailed understanding of the subsurface, especially, in view of 3D structures. As an example, the estimation of soil organic carbon stocks of ice complex deposits is currently accompanied by large uncertainties (Hugelius et al., 2014) and may be constrained by 3D structural models outlining major stratigraphic units. Here, we address the task of imaging 3D subsurface architecture in complex permafrost environments by ground-penetrating radar (GPR).

Several studies have demonstrated the potential of GPR for exploring permafrost environments, e.g., to estimate active-layer thickness (Arcone et al., 1998), to detect ground-ice bodies and ice layers (Yoshikawa et al., 2006; Brandt et al., 2007; De Pascale et al., 2008; Schwamborn et al., 2008), or to image specific periglacial morphologies (Doolittle et al., 1992; Moorman et al., 2003).

\footnotetext{
Manuscript received by the Editor 28 February 2015; revised manuscript received 1 October 2015; published online 29 January 2016.

${ }^{1}$ Universität Potsdam, Institut für Erd- und Umweltwissenschaften, Potsdam, Germany. E-mail: schennen@uni-potsdam.de; jens.tronicke@uni-potsdam.de; niklas.allroggen@uni-potsdam.de.

${ }^{2}$ Alfred-Wegener-Institut, Helmholtz-Zentrum für Polar- und Meeresforschung, Potsdam, Germany. E-mail: sebastian.wetterich@awi.de; georg. schwamborn@awi.de; lutz.schirrmeister@awi.de.

(C) 2016 Society of Exploration Geophysicists. All rights reserved.
} 
Although in many different GPR applications (e.g., in archaeology, sedimentology, hydrology), the benefits of 3D data collection and analysis have been acknowledged (e.g., Leckebusch, 2003; Grasmück et al., 2004; Tronicke et al., 2006; Bradford and Wu, 2007; Harper et al., 2010; Schmelzbach et al., 2011; Böniger and Tronicke, 2012), such 3D strategies have not yet been fully ex-

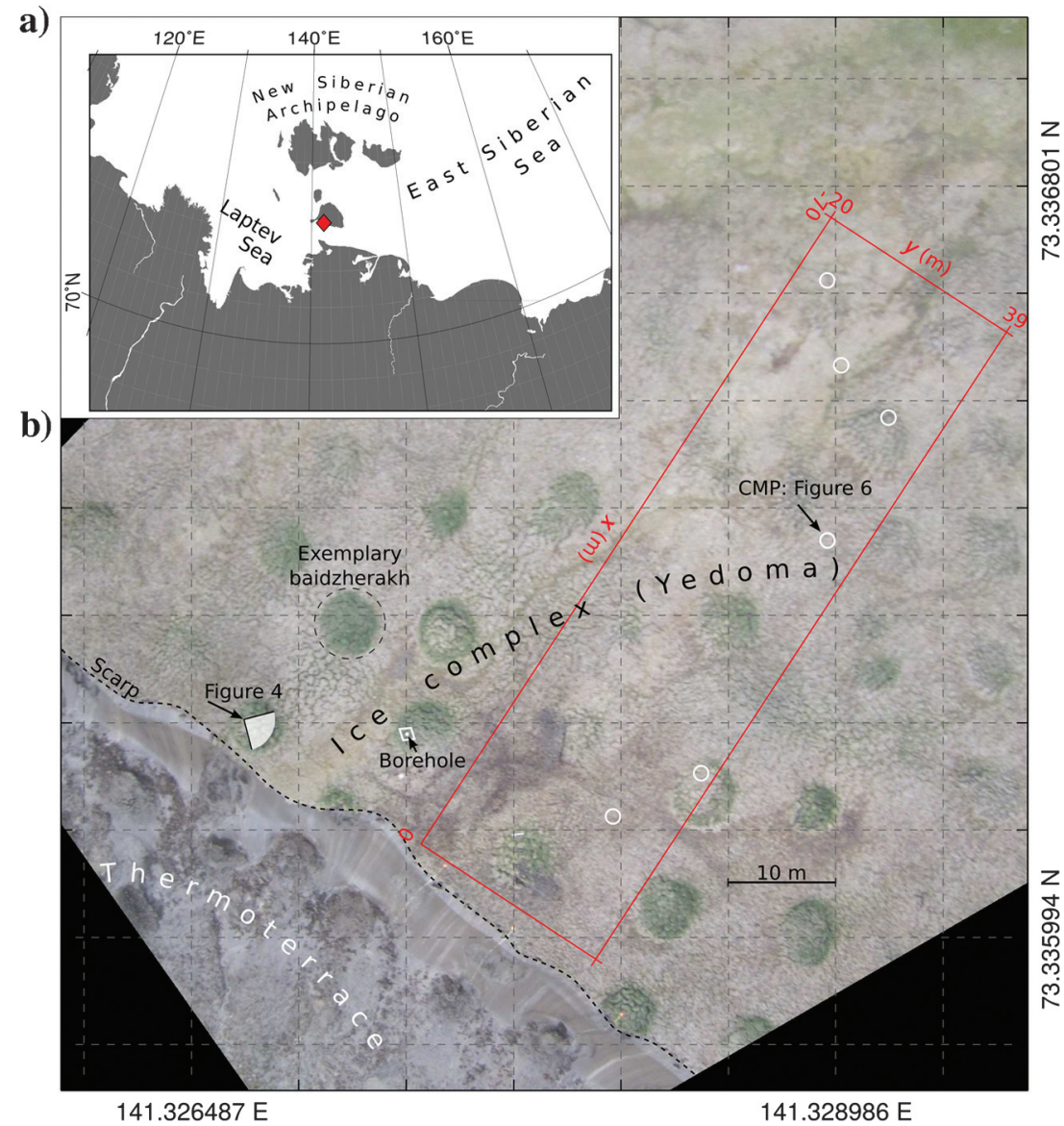

Figure 1. (a) Map of the New Siberian Archipelago in northern East Siberia. The red marker denotes the survey site at the southern coast of Bol'shoy Lyakhovsky Island. (b) Map and aerial photograph of our GPR survey area (red rectangle) located on a Yedoma hill. The circular shaped, densely vegetated thermokarst mounds (baidzherakhs) represent a prominent morphological feature. The southern end of the GPR survey area is closely located to a scarp (height difference approximately $18 \mathrm{~m}$ ) representing the transition from the elevated ice complex to the thermoterrace below. The white circles denote locations of CMP surveys.

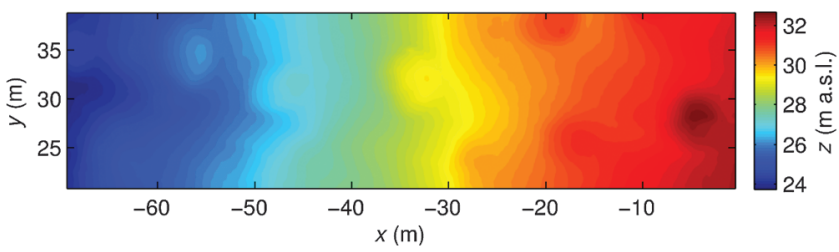

Figure 2. The digital terrain model of our survey site (Figure 1b) generated from positioning data recorded during GPR data acquisition. This DTM illustrates maximum elevation changes of approximately $10 \mathrm{~m}$ with a general decreasing trend toward the northeast where a major thermoerosional valley is located. Local minor topographic variations (up to approximately $1 \mathrm{~m}$ ) are associated with baidzherakhs, also highlighted in Figures $1 \mathrm{~b}$ and 4. ploited in permafrost environments. Up to now, only a limited number of case studies have been published. For example, Brosten et al. (2009) investigate active-layer characteristics beneath arctic streams using 3D GPR, whereas Munroe et al. (2007) study the near-surface geometry of ice-wedge polygons also using a 3D exploration strategy. Furthermore, most of the above-referenced permafrost applications of GPR focus on the uppermost soil layers (target depths $<5 \mathrm{~m}$ ) and the potential of 2D and, especially, 3D GPR to investigate subsurface permafrost structures at larger depths (i.e., >10 m) remains largely untapped.

In this study, we investigate the potential of 3D GPR imaging to locate and map major stratigraphic horizons expected at depths below $20 \mathrm{~m}$ in ice-rich permafrost deposits on Bol'shoy Lyakhovsky Island, northern East Siberia. In the following, after introducing our field site and the local geologic settings, we describe our GPR survey setup. After providing details regarding GPR data processing, we present our successfully migrated 3D data set, which is finally interpreted in terms of the major stratigraphic units.

\section{FIELD SITE}

\section{Site description}

Our study area is situated on Bol'shoy Lyakhovsky Island $\left(73.3^{\circ} \mathrm{N}, 141.3^{\circ} \mathrm{E}\right)$, which is the southernmost island of the New Siberian Archipelago located between the Laptev and the East Siberian seas (Figure 1a). The island is mostly covered by nonlithified sediments (Kyz'michev et al., 2006), and its surface consists of gradually sloping terrain intersected by rivers and thermoerosional valleys (Schirrmeister et al., 2011). Deposits of late Pleistocene ice complexes built Yedoma hills rising up to approximately $40 \mathrm{~m}$ above sea level (a.s.1.). These formations alternate with basins (diameter: 1$2 \mathrm{~km}, 12-15 \mathrm{~m}$ a.s.1.), which result from permafrost thawing (thermokarst). Our study site is located at the southern coast of the island along a Yedoma hillslope elevated between approximately 24 and $32 \mathrm{~m}$ a.s.l. (Figure 1b). As illustrated in Figure 1b, our 3D GPR survey covers an area of approximately $70 \times 20 \mathrm{~m}$. The southern edge of this area is located close to a scarp, which represents the transition from the investigated ice complex to a thermoterrace approximately $18 \mathrm{~m}$ below.

In Figure 2, we show a digital terrain model (DTM) generated from the positioning data recorded during kinematic GPR data acquisition. This DTM illustrates maximum elevation changes of approximately $10 \mathrm{~m}$ with a generally decreasing trend toward the northeast, in which a major thermoerosional valley is located. Local minor topographic variations (up to approximately $1 \mathrm{~m}$ ) are associated with thermokarst mounds (also termed baidzherakhs in Russian), which consist of former polygon fillings that were shaped by 
the meltout of surrounding ice wedges. These baidzherakhs are also visible on the aerial photographic image (Figure 1b) as circular features characterized by relatively dense vegetation (green colors). The uppermost decimeters of the subsurface comprise the activelayer thawed during our field campaign in summer 2014 up to depths of approximately 0.4-0.6 m (Schwamborn and Wetterich, 2015). Here, we know from field observations that soil moisture variations are roughly correlated with the local surface topography resulting in relatively dry baidzherakhs (representing local topographic heights) surrounded by areas of increased moisture (representing local topographic lows).

\section{Geologic setting and cryostratigraphy}

Numerous studies have investigated the stratigraphic framework exposed at the southern coast of Bol'shoy Lyakhovsky to reconstruct the paleoenvironmental history of northern East Siberia (e.g., Romanovskii, 1958; Meyer et al., 2002; Ilyashuk et al., 2006; Wetterich et al., 2009, 2011; Andreev et al. 2011; Schirrmeister et al., 2011). Our study area exposes four stratigraphic units (Yukagir Ice Complex Suite, Zimov'e Strata, Kuchchugui Suite, and Yedoma Ice Complex, named in accordance with Tumskoy, 2012), which are relevant for this study. In Figure 3, we characterize the deposits of these units in terms of absolute ice content in wt $\%$ (mass fraction, in grams per gram of dry sediment), TOC content in wt $\%$, and mean grain size. All deposits are typically sandy silts, but they differ considerably in absolute ice content and TOC content. Thus, we focus on these two most characteristic properties in the following stratigraphic description. Table 1 provides details about the geochronological data for all lithologic units. Our sediments and ice data are based on samples that were obtained in outcrops along the coastline at distances of $0.3-1.0 \mathrm{~km}$ from our survey area. These outcrop locations are presented as profiles L7-01, L7-03, L7-05, L14-10, and L14-11 in Schirrmeister et al. (2008) and Schwamborn and Wetterich (2015).

The first evidence for mid-Pleistocene permafrost on Bol'shoy Lyakhovsky Island is published in international literature by Schirrmeister et al. (2002) dating peat of the Yukagir Ice Complex Suite (Table 1). This suite is exposed up to approximately $3 \mathrm{~m}$ a.s.l. and is composed of ice-rich fine-grained sandy silts, moss peat, and syngenetic ice wedges. These ice wedges (up to $5 \mathrm{~m}$ wide at the top) intersect the sediment polygon fillings, which show an absolute ice content between 33 and $67 \mathrm{wt} \%$ and TOC content of up to $4 \mathrm{wt} \%$ (Figure 3).

The overlying Zimov'e Strata is approximately $0.5 \mathrm{~m}$ thick and is dated to approximately $134 \mathrm{ka}$ (Table 1 ). Deposits are characterized by frozen fine-grained sandy silts and clustered pebbles in sandy pockets. The unit is interpreted as paleoactive layers and characterized by ice contents between 19 and $22 \mathrm{wt} \%$ and relatively low TOC values between 0.4 and $1.9 \mathrm{wt}$ $\%$ (Figure 3).

Above the Zimov'e Strata ice poor, sandy silts of the Kuchchugui Suite reach a maximum thickness of up to approximately $12 \mathrm{~m}$. The formation ages range between 79 and $42 \mathrm{ka} \mathrm{BP}$ (Table 1). The sediments show horizontal layering and are interpreted as floodplain deposits, which are characterized by ice contents between 24 and $29 \mathrm{wt} \%$ and TOC largely $<1 \mathrm{wt} \%$ (Figure 3). Epigenetic sand-ice wedges of the Kuchchugui Suite may penetrate the Zimov'e Strata and reach into the Yukagir ice wedge.
The overlying Yedoma Ice Complex Suite is up to approximately $25 \mathrm{~m}$ thick (between approximately 10 and $35 \mathrm{~m}$ a.s.1.), and the deposition age ranges from 53 to $29 \mathrm{ka} \mathrm{BP}$ (Table 1). The corresponding ice-rich deposits are composed of sandy silts with an ice content of up to $63 \mathrm{wt} \%$ (Figure 3) in the upper part and typically much lower values $(30 \mathrm{wt} \%)$ toward the deposits of the underlying Kuchchugui Suite. Local, isolated peaty lenses and layers are reflected in the TOC data with values varying between 0.9 and $8.1 \mathrm{wt} \%$. Large ice wedges (exposed up to approximately $17 \mathrm{~m}$ in height and approximately $3-5 \mathrm{~m}$ in width) enclose soil accumulation in the ice-wedge polygon centers.

Data of the Yedoma Ice Complex Suite presented here have been adopted from Wetterich et al. (2014). Data of the Yukagir Ice Complex Suite, the Kuchchugui Suite, and the Zimov'e Strata are published here for the first time. The analysis and evaluation of data build on the methods of Wetterich et al. (2014).

\section{GPR DATA ACQUSITION AND PROCESSING}

In the summer of 2014, 3D GPR data were recorded across an area of approximately $70 \times 20 \mathrm{~m}$ at the southern coast of Bol'shoy Lyakhovsky Island (Figures $1 \mathrm{~b}$ and 4). We used a Sensors \& Software pulseEkko Pro GPR system equipped with a pair of $100 \mathrm{MHz}$ antennas and a Leica TPS1200 self-tracking total station for positioning (Figure 4). The antennas were fixed at a common offset of $1 \mathrm{~m}$ on a sledge, which was pulled across the survey area and automatically tracked by our total station. For navigation, we used a socalled GPS repeater display, which allowed us to display coordinates in real time during data acquisition (as described by Böniger and Tronicke, 2010b). More technical details regarding this kinematic surveying strategy are given by Böniger and Tronicke (2010a, 2010b). Using a time window of $500 \mathrm{ns,} \mathrm{a} \mathrm{sample} \mathrm{interval}$ of $0.2 \mathrm{~ns}$, and four vertical stacks, data were recorded in parallel lines in the southwest direction, i.e., parallel to the $x$-axis of the used local coordinate system (Figure 1b). Continuous recording resulted in approximately 100,000 irregularly distributed traces with an inline trace spacing of approximately $0.05 \mathrm{~m}$ and a crossline spacing of approximately $0.25 \mathrm{~m}$, which represents an appropriate data density as required for reliable 3D imaging (Grasmück et al., 2004). Furthermore, we acquired common midpoint (CMP) data to estimate subsurface velocities. These data were recorded using minimum and maximum source-receiver offsets of $0.15 \mathrm{~m}$ and up to $7 \mathrm{~m}$ and stepwise offset increments of $0.1 \mathrm{~m}$. The midpoint locations of our CMP surveys are indicated in Figure 1b.

Processing our 3D data set follows common practice and includes trace editing, latency correction (Böniger and Tronicke, 2010a),
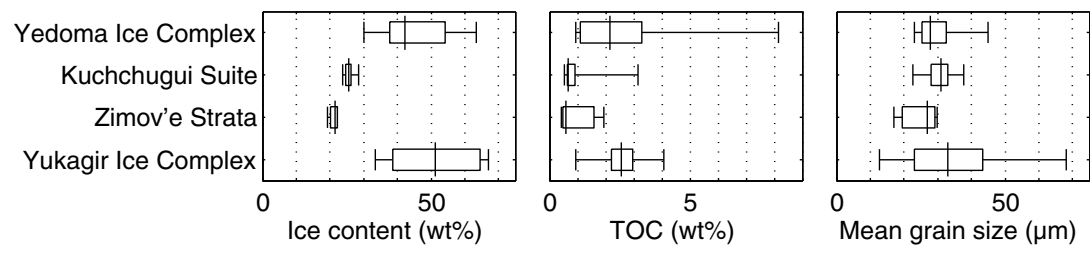

Figure 3. Characterization of deposits of dominant lithologic units in terms of absolute ice content (weight related to bulk mass), total organic carbon content, and arithmetic mean of grain size distribution. The box-and-whisker symbols show minimal and maximal values (whisker range) and 25-percentile, median, and 75-percentile (covered by box). Data presented for the Yedoma Ice Complex Suite are taken from Wetterich et al. (2014). 
Table 1. Ages of major lithologic units relevant for this study. Age determination focused on thorium ${ }^{230} /$ uranium $^{234}$ radioisotope disequilibria $\left({ }^{230} \mathrm{Th} / \mathrm{U}\right)$, infrared stimulated luminescence (IRSL), and radiocarbon $\left({ }^{14} \mathrm{C}\right.$, here ka in BP).

\begin{tabular}{lccc} 
Stratum & Age (ka) & Method & Published in \\
\hline Yedoma Ice Complex & $53-29$ & ${ }^{14} \mathrm{C}$ & Wetterich et al. (2014) \\
Kuchchugui Suite & $53-42$ & ${ }^{14} \mathrm{C}$ & Andreev et al. (2004) \\
& $79 \pm 14$ & IRSL & - \\
& $75 \pm 10$ & IRSL & - \\
Zimov'e Strata & $134 \pm 22$ & IRSL & Andreev et al. (2004) \\
Yukagir Ice Complex & $201 \pm 3$ & ${ }^{230} \mathrm{Th} / \mathrm{U}$ & $\begin{array}{c}\text { Schirrmeister } \\
\text { et al. (2002) }\end{array}$ \\
& & &
\end{tabular}

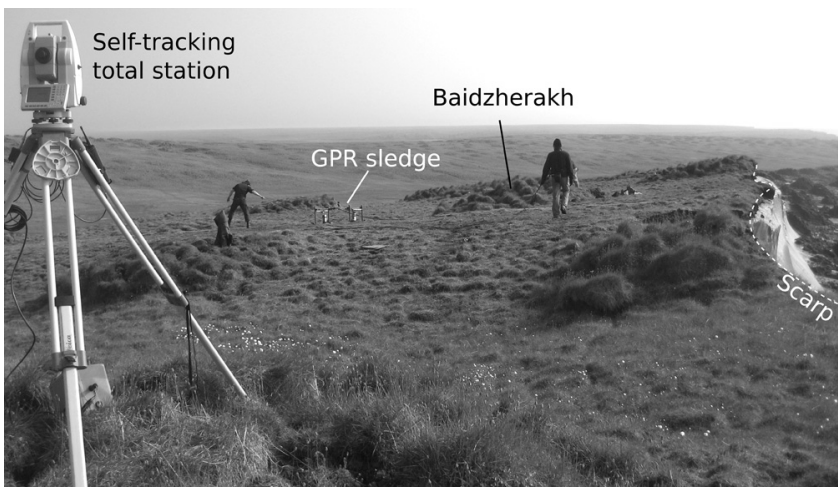

Figure 4. Photographic image of the survey site illustrating GPR data acquisition and site conditions. Direction of view is southeast (see also Figure 1b). The survey area is located in the central part of the image and exhibits several slightly elevated circular baidzherakhs with increased vegetation. Furthermore, a scarp (in total approximately $18 \mathrm{~m}$ in height) is visible, which is located at the southern end of our survey area. time-zero correction, DC removal, zero-phase band-pass filtering, natural neighbor-based gridding to a rectangular grid (with an inline point spacing of $0.05 \mathrm{~m}$ and a crossline spacing of $0.25 \mathrm{~m}$ of the gridded output data), and amplitude scaling. The data are processed in MATLAB, using internally developed GPR processing routines. The resulting unmigrated data are illustrated in Figure 5, in which we visualize our data cube in terms of a typical inline, crossline, and time slice after applying a topographic correction considering a constant velocity of $0.17 \mathrm{~m} / \mathrm{ns}$. Here, we observe coherent events up to traveltimes of approximately $400 \mathrm{~ns}$. Considering a velocity of $0.16-0.17 \mathrm{~m} / \mathrm{ns}$, this two-way traveltime corresponds to a maximal penetration depth of approximately $30 \mathrm{~m}$. In addition, we observe a rather regular pattern of areas with increased absorption, which are related to characteristic landform features known as baidzherakhs (see also Figure 1b). As also demonstrated by Figure 5, our unmigrated GPR data are characterized by complex 3D patterns of reflected and diffracted energy already indicating the need of 3D data acquisition and processing. Thus, our processing strategy also includes 3D frequency-wavenumber $(f-k)$ filtering (Galibert et al., 2002) and the application of an appropriate 3D migration scheme. The $f$ - $k$ filter is used to suppress steeply dipping events associated with diffraction tails (which are not successfully collapsed by the following migration) and out-of-plane reflections originating from a nearby scarp (see also Figure 1b). The used 3D migration routine aims at unraveling the discussed complex reflection patterns, also explicitly considering the topographic variations across our site (Figure 2). We use the 3D topographic migration scheme of Allroggen et al. (2015), which allows us to consider these topographic variations and also velocity variations associated with the contrast between the thawed active layer and the frozen material below.

The required rms velocity model has been established by analyzing available CMP data (location is shown in Figure 1b), diffraction hyperbolas in our common offset data, and evaluating the success of migration in an iterative manner. In the following, this step is discussed in more detail by presenting exemplary analyses of CMP and common-offset data. As an example of CMP data analysis, Figure 6 shows a selected CMP data set recorded in the central part of our survey area (Figure 1b). The figure includes an interpretation of the
Figure 5. Typical (a) inline, (b) crossline, and (c) time slice extracted from our unmigrated 3D GPR data set. Arrows indicate positions of target reflection features, and the dashed lines delineate the position of complementary data slices. a)

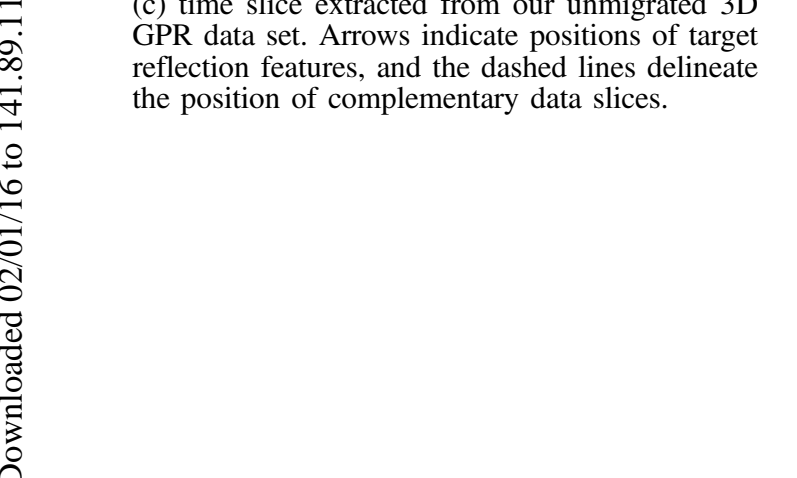

b)

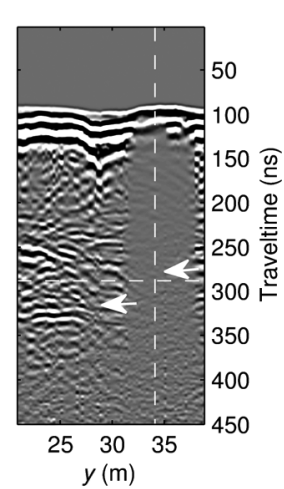


major primary events that were used to delineate our velocity model. Using visual inspection and linear-moveout-based analysis (Hamann et al., 2013), we estimate the velocities of the ground wave and the wave critically refracted at the interface between the active layer and the frozen ground. We only analyze these linear events because 3D effects (out-of-plane reflections and diffractions) and local topographic variations hinder a typical 1D normal-moveout-based analysis of reflected events. The velocities extracted from the remaining CMP data sets are largely consistent with the presented example, indicating a major velocity increase from approximately 0.06 to $0.17 \mathrm{~m} / \mathrm{ns}$ at the base of the active layer. To investigate possible velocity variations within the frozen ground, we analyze diffraction hyperbolas in our $3 \mathrm{D}$ common-offset data. As an example, Figure 7 shows four time slices extracted from our

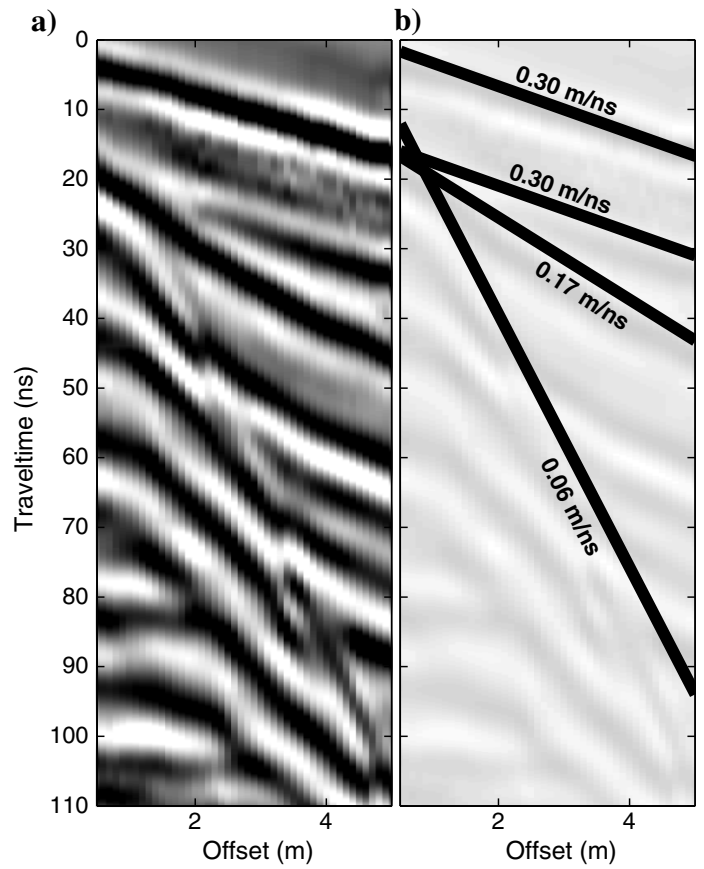

Figure 6. (a) The common-midpoint data set and (b) interpretation of events that were used to delineate an rms velocity model for 3D migration and time-to-depth conversion. We focused on the ground wave and critical refracted wave to estimate interval velocities of 0.06 and $0.17 \mathrm{~m} / \mathrm{ns}$, respectively.
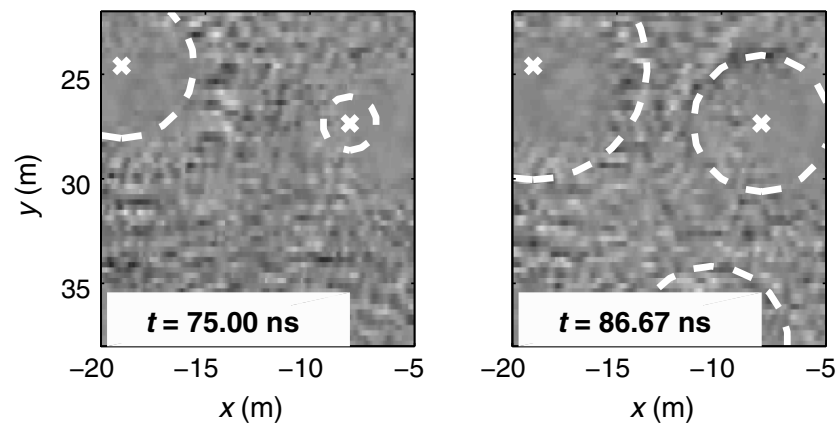

data cube at 75, 87, 98, and $110 \mathrm{~ns}$. As indicated by the dashed circles, the diffracted energy propagates with a velocity of approximately $0.17 \mathrm{~m} / \mathrm{ns}$. This value is in accordance with the velocity estimate from analyzing refraction events in CMP data. Thus, our final migration velocity model consists of two layers. The first layer represents the active layer (with a thickness of approximately $0.4 \mathrm{~m}$ and an interval velocity of $v_{\text {int }}=$ approximately $0.06 \mathrm{~m} / \mathrm{ns}$ ), whereas the second layer represents the underlying ice-rich permafrost $\left(v_{\text {int }}=0.17 \mathrm{~m} / \mathrm{ns}\right)$.

Figure 8 illustrates the final migrated data cube in terms of a typical inline, crossline, and time slice after applying a topographic correction considering a constant velocity of $0.17 \mathrm{~m} / \mathrm{ns}$. Comparing Figures 5 and 8 illustrates the success of the 3D migration scheme used because most diffraction hyperbolas have been properly collapsed, and the migrated data show better continuity as expected for a properly migrated image. To highlight the necessity of our 3D migration approach, we also illustrate the result obtained by using a 2D topographic migration approach (Figure 9). Comparing this with our 3D migration result (Figure 8) demonstrates that although the major lithologic boundaries are also indicated after $2 \mathrm{D}$ migration, the $3 \mathrm{D}$ image is more focused and shows improved continuity, especially for reflection events at traveltimes $>200 \mathrm{~ns}$. For example, in Figure 9a, approximately at $x=-65 \mathrm{~m}$ and $t=200 \mathrm{~ns}$, we observe upward-shaped amplitude patterns representing artifacts typically related to out-of-plane events. The improved continuity of the $3 \mathrm{D}$ migration result is also evident when comparing the time slices shown in Figures $8 \mathrm{c}$ and 9c. Thus, we conclude that a 3D surveying and processing strategy is inevitable to properly image subsurface structures present at our field site.

\section{RESULTS AND INTERPRETATION}

Figure 8 shows examples of 2D slices extracted from our final migrated data cube. We observe a band of high-energy early time phases covering the first approximately $60 \mathrm{~ns}$ after the first arrivals (Figure $8 \mathrm{a}$ and $8 \mathrm{~b}$ ). As learned from the CMP example (Figure 6), this band represents the interference pattern of the air wave, ground wave, a shallow reflection from the base of the active layer, an event critically refracted at this interface, and multiple events. At later traveltimes (up to approximately $250 \mathrm{~ns}$ ), we observe more discontinuous reflection patterns with reflection elements typically terminating after relatively short distances $(<10 \mathrm{~m})$. These features can be interpreted as locally perturbed deposits but may also represent

Figure 7. Sequence of four time slices in the southern part of our survey area. The circular annotations (white dashed lines) highlight the propagation of diffracted energy exhibiting a velocity of $0.17 \mathrm{~m} / \mathrm{ns}$.
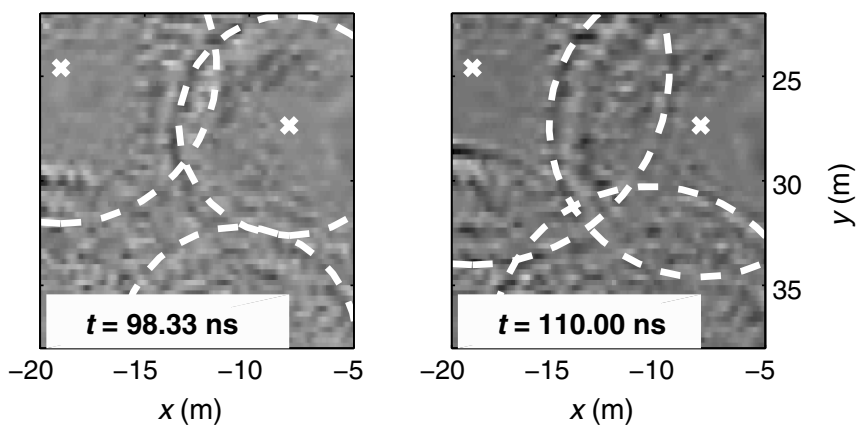
partly insufficiently migrated energy of, e.g., not fully collapsed diffraction hyperbolas. Between approximately 250 and $300 \mathrm{~ns}$, we observe horizontal to subhorizontal reflections in almost all inlines and crosslines (Figure $8 \mathrm{a}$ and $8 \mathrm{~b}$ ), i.e., these events are traceable through almost the entire data cube. The spatial continuity of this feature is indicated by the time slice as shown in Figure 8c. We interpret these reflections as a bounding surface laterally separating different stratigraphic units. Between approximately 300 and $350 \mathrm{~ns}$, a similar, although less distinct, feature is found, which we interpret as a second bounding surface (Figure $8 \mathrm{a}$ and $8 \mathrm{~b}$ ).

a)

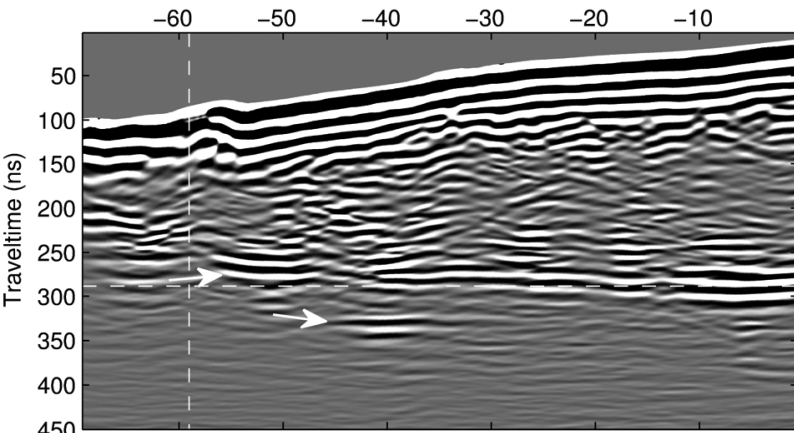

c)

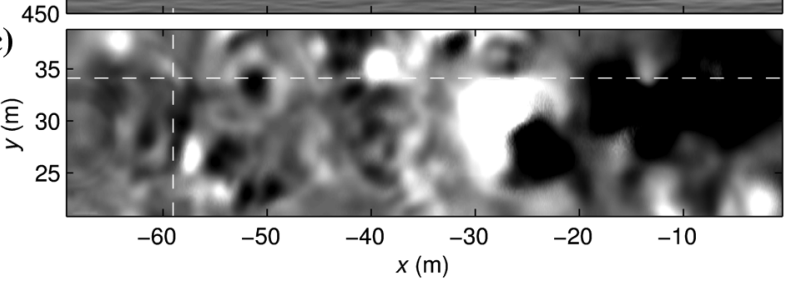

b)

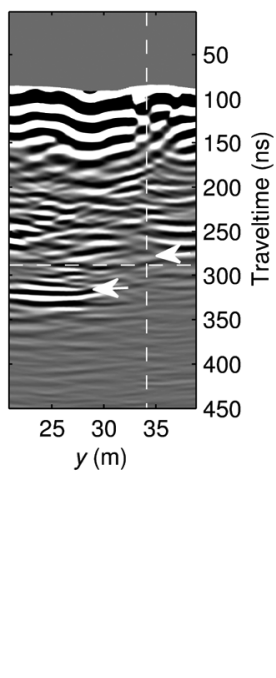

Figure 8. Typical (a) inline, (b) crossline, and (c) time slice extracted from our GPR data set after applying a 3D topographic migration. Arrows indicate interpreted reflection features, and the dashed lines indicate the position of complementary data slices.

a)

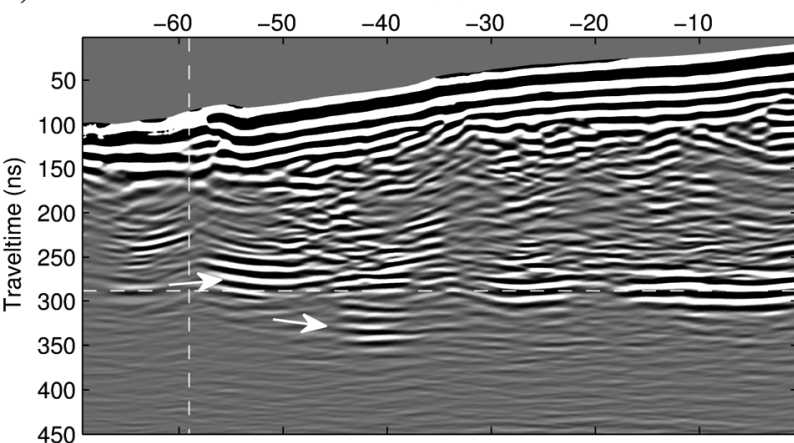

c)

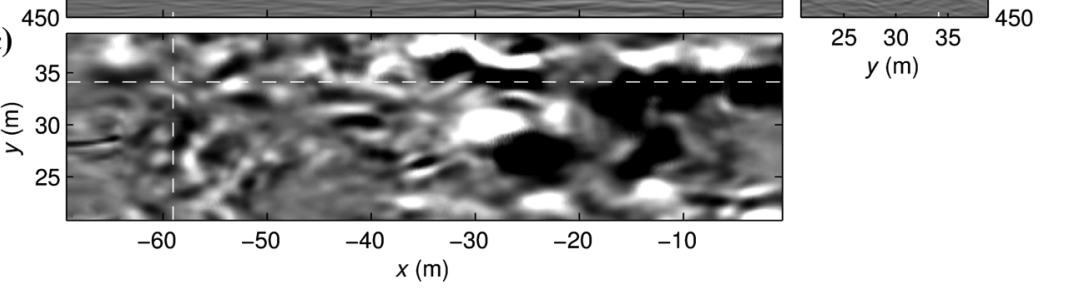

Figure 9. Typical (a) inline, (b) crossline, and (c) time slice extracted from our GPR data set after applying a 2D topographic migration. Arrows indicate interpreted reflection features, and the dashed lines indicate the position of complementary data slices.
Using the seismic interpretation software OpendTect, we further examine our migrated data cube and interpret the above discussed horizons approximately 275 and $325 \mathrm{~ns}$ in 3D. We pick both horizons semiautomatically by using tracking routines that, in an iterative manner, evaluate relative amplitude differences and similarity. For each horizon, we achieve a picking coverage of approximately ing the rms velocity model we described before.

The resulting horizon maps are illustrated in Figure 10, in which the positions of the horizons are shown in meters a.s.l. We roughly estimate the accuracy of the horizon depths to be in the order of $\pm 1 \mathrm{~m}$ by considering the vertical resolution capabilities of our data (wavelengths at this depth are approximately $1.7 \mathrm{~m}$ ) and typical velocity variations of diffracted energy in our common-offset data of approximately $\pm 5 \%$.

The upper horizon (Figure 10a) is located at a depth of approximately $11 \mathrm{~m}$ a.s.l. It exhibits a flat, horizontal shape and, considering our geologic setting and nearby borehole data, correlates with the depth of the major stratigraphic interface between the ice complex of the Yedoma Suite (median ice content of $42 \mathrm{wt} \%$ ) and the flood plain deposits of the Kuchchugui Suite (median ice content of $26 \mathrm{wt} \%$ ). This interpretation is in accordance with Schwamborn et al. (2008), who demonstrate that GPR is capable of imaging contrasts in ice content of approximately $30 \mathrm{wt} \%$. The second horizon (Figure 10b) is located at a depth of approximately $6.5 \mathrm{~m}$ a.s.1. Here, borehole data indicate two stratigraphic interfaces, which enclose the paleoactive layer of the Zimov'e Strata at the top (transition to floodplain deposits of the Kuchchugui Suite) and the bottom (transition to deposits of the Yukagir Ice Complex). However, the thickness of this stratigraphic unit (approximately $0.5 \mathrm{~m}$ ) is at or even beyond the resolution capability of our data characterized by wavelengths of approximately $1.7 \mathrm{~m}$. Because the contrast in ice content is more distinct at the lower interface (see Figure 3), we finally relate our second horizon (Figure 10b) to the transition from the floodplain deposits and the underlying paleoactive layer (median ice content of approximately 22 and $26 \mathrm{wt} \%$, respectively) to the Yukagir Ice Complex (median ice content of $51 \mathrm{wt} \%$ ).

With the above given interpretation of Figure 10, we are able to generate a 3D stratigraphic model that includes three of the major stratigraphic units present at our study site (Yedoma Ice Complex, Kuchchugui Suite, and Yukagir Ice Complex). This model is illustrated in Figure 11, in which we show a central vertical slice extracted from this 3D model. In addition, although not directly imaged by our GPR data, we included the Zimov'e Strata in this final stratigraphic model because the 
a)

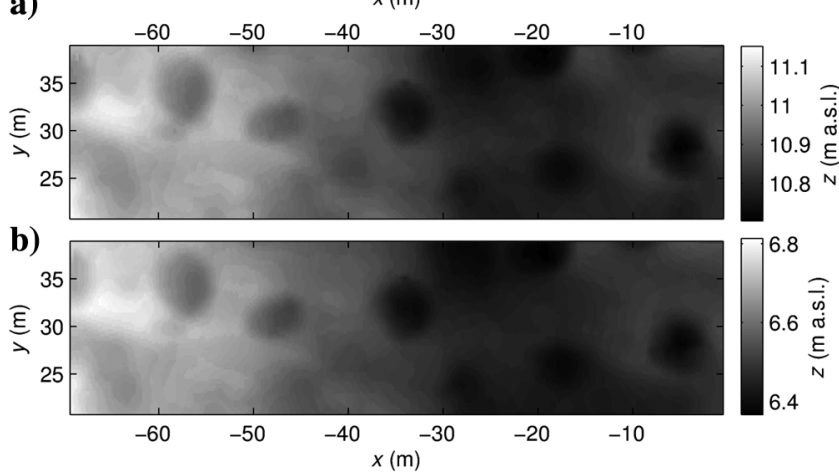

Figure 10. Horizon maps resulting from interpreting and picking two distinct, subhorizontal reflections (highlighted in Figures 5, 8, and 9). (a) The upper horizon is interpreted as the base of the Yedoma Ice Complex, and (b) the lower horizon is interpreted as the top of the Yukagir Ice Complex.

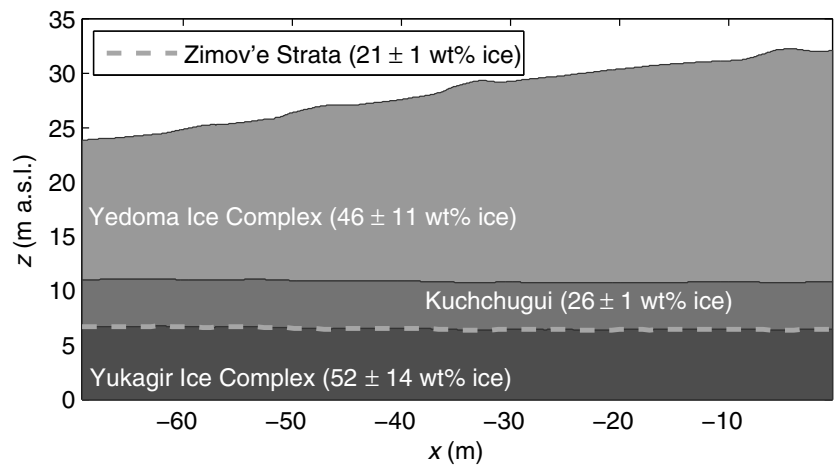

Figure 11. Final 3D cryostratigraphic model visualized in terms of a typical central-vertical profile (at $y=29.85 \mathrm{~m}$ ). In addition, we included the Zimov'e Strata, which was not resolvable in our GPR data. The position of these strata is well-constrained from our geologic background information (Schirrmeister et al., 2008).

stratigraphic position of this paleoactive layer is well-constrained from our geologic background information (Schirrmeister et al., 2008). Based on this stratigraphic model, existing outcrop and borehole data from various studies, such as presented by Andreev et al. (2009), Schirrmeister et al. (2011), and Wetterich et al. (2014), can be extrapolated in $3 \mathrm{D}$ and provide a framework for the subsurface characterization of periglacial morphologies. In addition, such GPR-derived stratigraphic models can improve the understanding of local processes, such as thermokarst, and can be used to estimate the potential of emission of climate relevant gases. Furthermore, our results can provide a valuable ground truthing for studies based on the remote sensing and constrain volumetric estimations of lithologic units, such as ice complex deposits or cryostructures within these.

\section{CONCLUSIONS}

We collected a 3D GPR data set using $100 \mathrm{MHz}$ antennas in the New Siberian Archipelago across a late Pleistocene Ice Complex (Yedoma), which is a typical formation of the periglacial lowlands in northern East Siberia. Our results demonstrate that GPR is capable of imaging interfaces between major stratigraphic units at depths of up to approximately $25 \mathrm{~m}$ below the ground surface.
The corresponding reflection events are associated with contrasts in absolute ice content of approximately $20 \mathrm{wt} \%$ between the different depositional formations. Furthermore, this case study illustrates that a 3D acquisition and processing strategy is crucial for reliably imaging rather deep target horizons in a complex permafrost environment such as our field site. A reliable identification of the picked target horizons would not be possible when using a 2D surveying strategy that hinders the identification and the correct handling of out-of-plane events. Furthermore, a properly processed 3D volume eases the interpretation including identification and tracking of subtle reflection events. Our final result is a 3D model outlining the dominant subsurface architecture, which is interpreted in terms of the major stratigraphic units present at our field location. This model can be used to easily upscale data from outcrops and/or boreholes and to establish a link to more classic geologic data sets and remote sensing images. As an example, our findings can be used to constrain the carbon stock estimation of the widely studied Yedoma deposits and serve as ground-truthed base level for remote sensing applications. Thus, we expect increasing interest and effort toward using 3D GPR for permafrost site characterization in depths of $>20 \mathrm{~m}$.

\section{ACKNOWLEDGMENTS}

We thank M. Dubnitzki, W. Schneider, and V. Zykov for technical and logistical support. Furthermore, we thank P. P. Overduin and three anonymous reviewers for valuable comments on our manuscript. For analyzing our 3D GPR data, we used OpendTect (http://www.opendtect.org/). We thank dGB Earth Sciences for making this software freely available for university research and education. We further gratefully acknowledge the German Federal Ministry of Education and Research (BMBF) for funding this study as part of the CARBOPERM project (03G0836B, 03G0836J).

\section{REFERENCES}

Allrogen, N., J. Tronicke, M. Delock, and U. Böniger, 2015, Topographic migration of $2 \mathrm{D}$ and $3 \mathrm{D}$ ground-penetrating radar data considering variable velocities: Near Surface Geophysics, 13, 253-259, doi: 10.3997/ 1873-0604.2014037.

Andreev, A. A., G. Grosse, L. Schirrmeister, S. A. Kuzmina, E. Y. Novenko, A. Bobrov, P. E. Tarasov, T. V. Kuznetsova, M. Krbetschek, H. Meyer, and V. V. Kunitsky, 2004, Late Saalian and Eemian palaeoenvironmental history of the Bol'shoy Lyakhovsky Island (Laptev Sea region, Arctic Siberia): Boreas, 33, 319-348, doi: 10.1080/03009480410001974.

Andreev, A. A., G. Grosse, L. Schirrmeister, T. V. Kuznetsova, S. A. Kuzmina, A. A. Bobrov, P. E. Tarasov, E. Y. Novenko, H. Meyer, A. Y. Derevyagin, F. Kienast, A. Bryantseva, and V. V. Kunitsky, 2009, Weichselian and Holocene palaeoenvironmental history of the Bol'shoy Lyakhovsky Island, New Siberian Archipelago, Arctic Siberia: Boreas, 38, 72-110, doi: 10.1111/bor.2009.38.issue-1.

Andreev, A., L. Schirrmeister, P. E. Tarasov, A. Ganopolski, V. Brovkin, C. Siegert, S. Wetterich, and H.-W. Hubberten, 2011, Vegetation and climate history in the Laptev Sea region (Arctic Siberia) during late Quaternary inferred from pollen records: Quaternary Science Reviews, 30, 21822199, doi: 10.1016/j.quascirev.2010.12.026.

Arcone, S. A., D. E. Lawson, A. J. Delaney, J. C. Strasser, and J. D. Strasser, 1998, Ground-penetrating radar reflection profiling of groundwater and bedrock in an area of discontinuous permafrost: Geophysics, 63, 1573-1584, doi: 10.1190/1.1444454.

Böniger, U., and J. Tronicke, 2010a, Kinematic GPR surveying using a modern TTS: Evaluating system cross-talk and latency: IEEE Transactions on Geoscience and Remote Sensing, 48, 3792-3798, doi: 10 $.1109 /$ TGRS.2010.2048332.

Böniger, U., and J. Tronicke, 2010b, Improving the interpretability of 3D GPR data using target-specific attributes: Application to tomb detection: Journal of Archaeological Science, 37, 672-679, doi: 10.1016/j.jas.2010.01.013.

Böniger, U., and J. Tronicke, 2012, Subsurface utility extraction and characterization: Combining GPR symmetry and PCA polarization attributes: IEEE Transactions on Geoscience and Remote Sensing, 50, 736-746, doi: 10.1109/TGRS.2011.2163413. 
Bradford, J. H., and Y. Wu, 2007, Instantaneous spectral analysis: Time-frequency mapping via wavelet matching with application to 3D GPR contaminated site characterization: The Leading Edge, 26, 1018-1023, doi: $10.1190 / 1.2769559$

Brandt, O., K. Langley, J. Kohler, and S.-E. Hamran, 2007, Detection of buried ice and sediment layers in permafrost using multi-frequency ground penetrating radar: A case examination on Svalbard: Remote Sensing of Environment, 111, 212-227, doi: 10.1016/j.rse.2007.03.025.

Brosten, T. R., J. H. Bradford, J. P. McNamara, M. N. Gooseff, J. P. Zarnetske, W. B. Bowden, and M. E. Johnston, 2009, Estimating 3D variation in active-layer thickness beneath arctic streams using ground-penetrating radar: Journal of Hydrology, 373, 479-486, doi: 10.1016/j.jhydrol.2009 .05 .011 .

De Pascale, G. P., W. H. Pollard, and K. K. Williams, 2008, Geophysical mapping of ground ice using a combination of capacitive coupled resistivity and ground-penetrating radar, Northwest Territories, Canada: Journal of Geophysical Research, 113, F02S90, doi: 10.1029/2006JF000585.

Doolittle, J. A., M. A. Hardisky, and S. Black, 1992, Ground-penetrating radar study of Goodream palsas, Newfoundland, Canada: Arctic and Alpine Research, 24, 173-178, doi: 10.2307/1551537.

Galibert, P. Y., L. Duval, and R. Dupont, 2002, Practical aspects of 3D coherent noise filtering using $(f-k x-k y)$ or wavelet transform filters: 72nd Annual International Meeting, SEG, Expanded Abstracts, 2241-2244.

Grasmueck, M., R. Weger, and H. Horstmeyer, 2004, Three-dimensional ground-penetrating radar imaging of sedimentary structures, fractures, and archaeological features at submeter resolution: Geology, 32, 933936, doi: 10.1130/G20776.1.

Grosse, G., J. E. Robinson, R. Bryant, M. D. Taylor, W. Harper, A. DeMasi, E. Kyker-Snowman, A. Veremeeva, L. Schirrmeister, and J. Harden, 2013 Distribution of late Pleistocene ice-rich syngenetic permafrost of the Yedoma Suite in east and central Siberia, Russia: USGS Open-File Report, 1078, http://pubs.usgs.gov/of/2013/1078/, accessed 26 February 2015.

Hamann, G. J. Tronicke, C. Steelman, and A. Endres, 2013, Spectral velocity analysis for determination of ground wave velocities and their uncertainties in multi-offset GPR data: Near Surface Geophysics, 11, 167-176, doi: 10.3997/1873-0604.2012038.

Harper, J. T., J. H. Bradford, N. F. Humphrey, and T. W. Meierbachtol, 2010, Vertical extension of the subglacial drainage system into basal crevasses: Nature, 467, 579-582, doi: 10.1038/nature09398.

Hugelius, G., J. Strauss, S. Zubrzycki, J. W. Harden, E. A. G. Schuur, C.-L. Ping, L. Schirrmeister, G. Grosse, G. J. Michaelson, C. D. Koven, J. A O’Donnell, B. Elberling, U. Mishra, P. Camill, Z. Yu, J. Palmtag, and P. Kuhry, 2014, Estimated stocks of circumpolar permafrost carbon with quantified uncertainty ranges and identified data gaps: Biogeosciences, 11, 6573-6593, doi: $10.5194 / \mathrm{bg}-11-6573-2014$.

Ilyashuk, B. P., A. A. Andreev, A. A. Bobrov, V. E. Tumskoy, and E. A Ilyashuk, 2006, Interglacial history of a palaeo-lake and regional environment: A multi-proxy study of a permafrost deposit from Bol'shoy Lyakhovsky Island, Arctic Siberia: Journal of Palaeolimnology, 35, 855-872, doi: 10.1007/s10933-005-5859-6.

Kyz'michev, A. B., A. V. Soloviev, V. E. Gonikberg, M. N. Shapiro, and O. V. Zamzhitskii, 2006, Mesozoic syncollision siliciclastic sediments of the Bols'shoi Lyakhov Island (New Siberian Islands): Stratigraphy and Geological Correlation, 14, 30-48, doi: http://doi.org/10.1134/ S0869593806010035.

Leckebusch, J., 2003, Ground-penetrating radar: A modern three-dimensional prospection method: Archaeological Prospection, 10, 213-240, doi: $10.1002 /$ arp. 211

Meyer, H., A. Y. Dereviagin, C. Siegert, L. Schirrmeister, and H.-W. Hubberten, 2002, Palaeoclimate reconstruction on big Lyakhovsky Island, North Siberia - Hydrogen and oxygen isotopes in ice wedges: Permafrost and Periglacial Processes, 13, 91-105, doi: 10.1002/ppp.416.

Moorman, B. J., S. D. Robinson, and M. M. Burgess, 2003, Imaging periglacial conditions with ground-penetrating radar: Permafrost and Periglacial Processes, 14, 319-329, doi: 10.1002/ppp.463.

Munroe, J. S., J. A. Doolittle, M. Z. Kanevskiy, K. M. Hinkel, F. E. Nelson, B. M. Jones, Y. Shur, and J. M. Kimble, 2007, Application of groundpenetrating radar imagery for three-dimensional visualisation of near-surface structures in ice-rich permafrost, Barrow, Alaska: Permafrost and Periglacial Processes, 18, 309-321, doi: 10.1002/ppp.594.

Romanovskii, N. N., 1958, Novye dannye o stroenii chetvertichnykh otlozhenii ostrova Bol'shoy Lyakhovsky, Novosibirskie Ostovava (New data about the structure of Quaternary deposits of Bol'shoy Lyakhovsky Island, New Siberian Islands): Nauchnye doklady vysshei shkoly. Seriya geologogeograficheskaya, 2, 243-248 (in Russian).

Schirrmeister, L., V. Kunitsky, G. Grosse, S. Wetterich, H. Meyer, G Schwamborn, O. Babiy, A. Derevyagin, and C. Siegert, 2011, Sedimentary characteristics and origin of the Late Pleistocene Ice Complex on north-east Siberian Arctic coastal lowlands and islands - A review: Quaternary International, 241, 3-25, doi: 10.1016/j.quaint.2010.04.004.

Schirrmeister, L., D. Oezen, and M. A. Geyh, $2002,{ }^{230} \mathrm{Th} / \mathrm{U}$ dating of frozen peat, Bol'shoy Lyakhovsky Island (North Siberia): Quaternary Research, 57, 253-258, doi: 10.1006/qres.2001.2306.

Schirrmeister, L., S. Wetterich, V. Tumskoy, and D. Dobrynin, 2008, Palaeoenviromental studies on Bol'shoy Lyakhovsky Island, in J. Boike, D. Y. Bolshiyanov, L. Schirrmeister, and S. Wetterich, eds., Russian-German cooperation SYSTEM LAPTEV SEA: The expedition Lena - new Siberian islands 2007 during the International Polar Year 2007/2008: Reports on polar and marine research, 584, 51-84.

Schmelzbach, C., J. Tronicke, and P. Dietrich, 2011, Three-dimensional hydrostratigraphic models from ground-penetrating radar and direct-push data: Journal of Hydrology, 398, 235-245, doi: 10.1016/j.jhydrol.2010.12.023.

Schwamborn, G., J. Heinzel, and L. Schirrmeister, 2008, Internal characteristics of ice-marginal sediments deduced from georadar profiling and sediment properties (Brøgger Peninsula, Svalbard): Geomorphology, 95, 7483, doi: 10.1016/j.geomorph.2006.07.032

Schwamborn, G., and S. Wetterich, 2015, Russian-German cooperation CARBOPERM: Field campaigns to Bol'shoy Lyakhovsky Island in 2014: Reports on polar and marine research, 686, 5-44, http://epic.awi .de/37311/1/BzPM_0686_2015.pdf, accessed 26 February 2015.

Strauss, J., L. Schirrmeister, G. Grosse, S. Wetterich, M. Ulrich, U. Herzschuh, and H.-W. Hubberten, 2013, The deep permafrost carbon pool of the Yedoma region in Siberia and Alaska: Geophysical Research Letters, 40, 6165-6170, doi: 10.1002/2013GL058088.

Strauss, J., L. Schirrmeister, S. Wetterich, A. Borchers, and S. P. Davydov, 2012, Grain-size properties and organic-carbon stock of Yedoma Ice Complex permafrost from the Kolyma lowland, northeastern Siberia: Global Biogeochemical Cycles, 26, GB3003, doi: 10.1029/ 2011 GB004104.

Tarnocai, C., J. G. Canadell, E. A. G. Schuur, P. Kuhry, G. Mazhitova, and S. Zimov, 2009, Soil organic carbon pools in the northern circumpolar permafrost region: Global Biogeochemical Cycles, 23, GB2023, doi: 10.1029/2008GB003327.

Tronicke, J., P. Villamor, and A. G. Green, 2006, Detailed shallow geometry and displacement estimates of the Maleme Fault Zone, New Zealand, using 2-D and 3-D georadar: Near Surface Geophysics, 4, 155-161, doi: 10 .3997/1873-0604.2005041.

Tumskoy, V. E., 2012, Osobennosti kriolitogeneza otlozhenii severnoi Yakutii v srednem Neopleistotsene-Golotsene (Peculiarities of cryolithogenesis in northern Yakutia from the Middle Neopleistocene to the Holocene): Kriosfera Zemli, 16, 12-21 (in Russian).

Ulrich, M., G. Grosse, J. Strauss, and L. Schirrmeister, 2014, Quantifying wedge-ice volumes in Yedoma and Thermokarst basin deposits: Permafrost and Periglacial Processes, 25, 151-161, doi: 10.1002/ppp. v25.3.

Wetterich, S., N. Rudaya, V. Tumskoy, A. A. Andreev, T. Opel, L. Schirrmeister, and H. Meyer, 2011, Last glacial maximum records in permafrost of the East Siberian Arctic: Quaternary Science Reviews, 30, 3139-3151, doi: 10.1016/j.quascirev.2011.07.020.

Wetterich, S., L. Schirrmeister, A. A. Andreev, M. Pudenz, B. Plessen, H. Meyer, and V. V. Kunitsky, 2009, Eemian and Late Glacial/Holocene palaeoenvironmental records from permafrost sequences at the Dmitry Laptev Strait (NE Siberia, Russia): Palaeogeography, Palaeoclimatology, Palaeoecology, 279, 73-95, doi: 10.1016/j.palaeo.2009.05.002.

Wetterich, S., V. Tumskoy, N. Rudaya, A. A. Andreev, T. Opel, H. Meyer, and L. Schirrmeister, 2014, Ice complex formation in arctic East Siberia during the MIS3 Interstadial: Quaternary Science Reviews, 84, 39-55, doi: 10.1016/j.quascirev.2013.11.009.

Yoshikawa, K., C. Leuschen, A. Ikeda, K. Harada, P. Gogineni, P. Hoekstra, L. Hinzman, Y. Sawada, and N. Matsuoka, 2006, Comparison of geophysical investigations for detection of massive ground ice (pingo ice): Journal of Geophysical Research: Planets, 111, 2156-2202, doi: 10 .1029/2005JE002573. 